\title{
AVALIAÇÃO DA MOBILIDADE EM MUNICÍPIO POLO DA ZONA DA MATA MINEIRA
}

\author{
Josimar Catarina Gonçalves Dutra ${ }^{1}$ \\ Maycown Roberto Amaral da Costa² \\ Lidiane Espindula ${ }^{3}$
}

Resumo: Esta pesquisa apresenta parte de um estudo acerca da mobilidade do Município de ManhuaçuMG, um dos elementos que compõem a avaliação base para a revisão do Plano Diretor do município (em andamento). Tendo em vista o crescimento acelerado do processo de urbanização das cidades brasileiras, principalmente a partir da segunda metade do Séc. $X X$, diversos polos se formaram, entre eles em Manhuaçu, que atende cerca de trinta municípios da região. A partir de pesquisas na Prefeitura Municipal e pesquisa de observação na Sede do Município, o estudo apresenta a necessidade de ações emergentes por parte da municipalidade para soluções quanto a mobilidade, sobretudo na Sede.

Palavras-chave: Plano Diretor; Circulação; Qualidade de vida; Manhuaçu.

\footnotetext{
1 Arquitetura e Urbanismo/FACIG - Faculdade de Ciências Gerenciais de Manhuaçu, Brasil. E-mail: josymarkataryna2010@gmail.com.

2 Arquitetura e Urbanismo/FACIG - Faculdade de Ciências Gerenciais de Manhuaçu, Brasil. E-mail: maicownroberto@hotmail.com.

3 Arquitetura e Urbanismo/FACIG - Faculdade de Ciências Gerenciais de Manhuaçu, Brasil. E-mail: espindulaprojetos@gmail.com.
} 